\title{
Current Status of Mitral Valve Repair
}

\author{
MOHAMMED Sh.H. ABDALLAH, M.D.*; OSAMA S. ABD EL-MONEM, M.D.**; \\ MOHAMMED A. HASSAN, M.D.* and TAMER A.K. MOHAMED, M.Sc.* \\ The Department of Cardiothoracic Surgery, Faculty of Medicine, Al-Azhar University* and \\ The Department of Cardiac Surgery, National Heart Institute**
}

\begin{abstract}
Background: Techniques of MV repair have undergone many modifications and improvements in the last three decades, which have made it a more predictable and reproducible method either in rheumatic or degenerative mitral valve repair.

Aim of Study: 1- Comparing the results of repairing degenerative mitral valve versus the rheumatic pathology. 2Assessment the results of resectional technique (excising part of valve leaflet) and the respect one (preserving the valve leaflet without excision any part of it) for posterior leaflet prolapse during the degenerative mitral valve repair.

Patients and Methods: This prospective study was conducted in the Department of Cardiac Surgery, National Heart Institute (NHI) from July 2014 to December 2017 including postoperative follow-up at 6 months. One hundred cases with severe mitral valve regurgitation underwent mitral valve repair divided into two groups: Group " $\mathrm{D}$ " where 50 cases had degenerative mitral valve pathology with a predominant mitral regurgitation and Group " $R$ " where 50 cases had rheumatic valve disease with a predominant mitral regurgitation and high likelihood of repair. Techniques used for repair of prolapsed degenerative PML divided into resection technique and respect one.
\end{abstract}

Results: As regards comparison between Group " $\mathrm{D}$ " versus Group " $R$ " there was significant increase in MV area, MPAP and mean diastolic gradient of MV in group " $D$ " than group "R" at 6 months of post-operative follow-up. Five cases in Group " $\mathrm{R}$ " had a mean diastolic mitral gradient more than $10 \mathrm{mmHg}$ that needed mitral valve replacement, four cases of them were post leaflets' shaving and decalcification. Degree of residual mitral regurgitation in Group " $D$ " included 41 $(82 \%)$ cases with no or trivial regurgitation while $9(18 \%)$ cases were mild, whereas in group " $R$ " $37(74 \%)$ cases had no or trivial regurgitation, $9(18 \%)$ had mild mitral regurgitation, $2(4 \%)$ was mild to moderate and $2(4 \%)$ cases had moderate mitral regurgitation that needed further follow-up with echocardiography every 6 months. Comparison between resection technique versus respect one revealed a significance difference between both groups as regards MVA and size of the ring annuloplasty but no significance difference was found between both groups as regards degree of residual MV regur-

Correspondence to: Dr. Mohammed Sh.H. Abdallah, The Department of Cardiothoracic Surgery, Faculty of Medicine, Al-Azhar University gitation or mean diastolic MV gradient after 6 months of follow-up.

Conclusions: The early postoperative results for posterior mitral leaflet repair with respect technique using Uniscalloping of posterior leaflet or artificial chordae-ePTFE-is very acceptable and recommended. Using of artificial chordae to AML is very effective and safe to solve the problem of leaflet prolapse. Rheumatic valve repair appears to be possible in selected cases with rheumatic mitral valve dysfunction. Leaflet procedures in rheumatic valve repair may be associated with reduced durability of rheumatic MV repair.

Key Words: Rheumatic mitral valve - Posterior leaflet prolapse - Extended PolyTetraFluoroEthylene - Respect technique - Resect technique.

\section{Introduction}

MITRAL valve repair is currently considered to be superior to MV replacement. It offers improved perioperative and long-term survival, greater regression of left ventricular dimensions and maintenance of left ventricular function [1].

The durability of mitral repair is at least equivalent to replacement and offers freedom from longterm anticoagulation [2].

Surgical repair of the MV is the preferred goal of modern MV surgery, with the use of prosthetic valves reserved for a select patient population [3]

Techniques of MV repair have undergone many modifications and improvements in the last 50 years, which have made it a more predictable and reproducible method [4].

The classic operation designed by Carpentier involved cutting out the ruptured cord segment of the posterior leaflet and creating advancement flaps of the whole posterior leaflet of the mitral valve. However, many surgeons were worried that cutting the posterior leaflet of the annulus could result in complications [5]. 
Mitral valve repair techniques popularized in the last decade include the use of artificial chordae with extended PolyTetraFluoroEthylene (ePTFE) sutures for anterior and posterior mitral leaflet pathology. These technical improvements have enabled the successful repair of more complex MV disease [6].

The goal of this approach is to correct the prolapse by using e-PTFE suture neochordae without leaflet resection to resuspend the free edge of the mitral valve leaflet. Artificial chordae has been used to repair mitral valves for more than 25 years with an excellent long-term durability has been reported [7]

Several advantages push us toward this technique in respecting the tissue of the posterior leaflet one of them is that the goal of mitral valve repair relies on the restoration of a good surface of coaptation to ensure a satisfactory function of the mitral valve. Leaflet tissue is the primary component defining the surface of coaptation, and it may be preferable to preserve as much of the leaflet tissue, as opposed to resecting a significant portion of it [8].

Though mitral valve repair has become the procedure of choice for degenerative mitral regurgitation, its use for correction of rheumatic mitral regurgitation has remained scant, because repair is technically more difficult and is associated with a higher failure rate in this group [9].

Repairing of mixed lesions is technically more challenging than managing of pure MR lesions. Durability of pure MR repair is much higher than that of mixed lesion repair [10].

The goal of our prospective study is to compare the results of repair in rheumatic mitral valve with the degenerative mitral pathology and to assess the results of resectional technique versus the respect one for PLP during the degenerative mitral valve repair.

\section{Patients and Methods}

This prospective study was conducted in the Department of Cardiac Surgery, National Heart Institute (NHI) from July 2014 to December 2017 including post-operative follow-up at 6 months. One hundred cases with severe mitral valve regurgitation underwent mitral valve repair were divided into two groups: Group "D" where 50 cases had degenerative mitral valve pathology with a pure mitral regurgitation and Group " $\mathrm{R}$ " where 50 cases had rheumatic valve disease with a predominant mitral regurgitation and high likelihood of repair. Techniques used in the degenerative PML were divided into resection technique and respect one.

Inclusion criteria included: Cases with chronic severe mitral regurgitation due to either rheumatic or degenerative etiology, both sexes, with age more than 18 years, with or without tricuspid incompetence.

Exclusion criteria included: Cases with predominant mitral stenosis, redo heart surgery, associated coronary heart disease requiring coronary artery bypass surgery, aortic valve disease necessitating aortic valve replacement, cases with infective endocarditis.

\section{Operative technique:}

All cases were operated through median sternotomy incision. Cannulation for bypass was carried in the ascending aorta for arterial perfusion and by two separate venous cannulae for venous return in SVC and IVC. Left atriotomy through (Sondergaard's groove) was made for all cases. The mitral valve was evaluated for the feasibility of valve repair according to its anatomic and pathological features confirming data obtained by TEE Fig. (1). Mitral valve was dealt with by different reparative techniques according to its apparent pathology and anatomy attempting to reverse the mechanism of regurgitation.

Criteria for rheumatic valves which had a likelihood for repair included pre-operatively a predominant regurgitation, mitral valve area $\sim 2 \mathrm{~cm}$ (we accepted till $1.8 \mathrm{~cm}^{2}$ ), AML height $>2.4 \mathrm{~cm}$ and diagnosis of mitral stenosis depending on high transvalvular mitral gradient $\geq 8 \mathrm{mmHg}$ by Doppler. Intraoperative criteria included minimal or no commissural fusion, intact chordae tendineae with no aberrant shortening or fusion, also mobile and pliable-nearly transparent-leaflets.

Repair used during our study for posterior leaflets prolapse included either resectional or respect techniques. Rectangular resection was done with or without leaflet foldingplasty (plication) if there was extensive portion of posterior leaflet prolapsed. Sutures used in resection were Polybutylate Coated Braided Polyester Suture (Ethicon X872H Suture 3-0 Ethibond 30" GRN Braided RB-1).

Respect technique was used in cases with limited prolapsing part of $\mathrm{P} 2$ scallop the prolapsed portion of posterior mitral leaflet was sutured to 
the adjacent normally supported portion of the posterior leaflet (from both sides) using 3-0 Ethibond suture in a process called uniscalloping Fig. (2).

Artificial neochordae may be used when needed for the prolapsed area by taking the measured normal chordae tendineae as a guide that must fill two parameters: (I) Thick normal chorda (II) Proper length reaching healthy leaflet tissue.

Sutures used as artificial neochordae in any leaflet were CV-4 artificial monofilament suture expanded polytetrafluoroethylene (ePTFE) (GoreTex W, W.L. Gore and Associates, Flagstaff, AZ, USA).

Cases with rheumatic mitral valve having a restricted and calcified posterior mitral leaflet needed shaving, thinning, decalcification and mobilization of the posterior leaflet by cutting the tethering ones, in order to increase its mobility and pliability to ensure opening and proper closure of the valve without regurgitation.

Artificial chordae were the standard during anterior leaflet prolapse repair. They were inserted to either posteromedial or anterolateral papillary muscles due to elongation of chordae tendineae group causing extensive prolapse. Triangular resection was done in an exceptional few cases, when AML was voluminous and the prolapsed portion was very limited. For bileaflet repair we used any of previous techniques when needed for repairing any leaflet.

Shaving, thinning, decalcification and mobilization of the anterior leaflet was done in cases with restricted, calcific rheumatic anterior valve pathology, in order to increase its mobility and pliability to ensure opening and proper closure of the valve without regurgitation. The artificial chordae may be used anterior rheumatic leaflet prolapse. Minimal bilateral commissurotomy was used for releasing of the fused commis sure while chordal shortening was done when there was anterior leaflet prolapse. Ring annuloplasty was a standard for all cases either rheumatic or degenerative.

All cases were transferred to the ICU where they were maintained on positive pressure ventilation with continuous monitoring of the vital signs. The cases were weaned off the ventilator according to the standard criteria. Oral anticoagulant was started in the second postoperative day in all cases and maintained for 3 months, it was adjusted to keep the International Normalized Ratio (INR) ranging between 2-3. After 3 months, anticoagulant treatment was discontinued provided that the patient was in sinus rhythm.

\section{Follow-up:}

Six months after surgery cases were rechecked for NYHA class, rhythm and complete echocardiographic Doppler study which was repeated for all cases.

\section{Statistical analysis:}

Data were analyzed using MedCalc $\odot$ version 18.2.1 (MedCalc@ Software bvba, Ostend, Belgium). Continuous numerical variables were presented as mean and SD and inter-group differences were compared using the unpaired $t$-test. Categorical variables were presented as ratio or as number and percentage and differences were compared using the Pearson chi-squared test or Fisher's exact test. Ordinal data were compared using the chisquared test for trend. Two-sided $p$-value $<0.05$ was considered statistically significant.

\section{Results}

A- Comparison between $M V$ repair in the degenerative group versus rheumatic pathology:

\section{Pre-operative clinical data:}

Pre-operative clinical characteristics of cases with degenerative or rheumatic mitral valve disease as regards symptoms depended on NYHA class and rhythm. No significant difference between both groups as regards NYHA class ( $p$-value $=$ $0.205)$, but there was significant difference between both groups as regards rhythm as $11(22 \%)$ cases in group "D" had AF while 20 (40\%) group "R" had AF. The routine pre-operative investigations and complete resting transthoracic echocardiographic Doppler study (TTE) shown in (Table 1).

\section{Operative results:}

37 cases had only posterior degenerative leaflet prolapse. Rectangular resection was done with or without leaflet plication for 15 cases with an extensive portion of prolapse, while respect technique using posterior leaflet uniscalloping was done in 22 cases with a limited prolapsing portion of $\mathrm{P} 2$ scallope Fig. (3), 5 cases of them needed a concomitant artificial neochordae.

12 cases with rheumatic mitral valve having a restricted posterior mitral leaflet needed shaving, thinning, decalcification and mobilization of the thickened and fibrotic posterior leaflet, 5 cases of them needed concomitant mild shaving of the anterior leaflet and 4 cases needed concomitant commissurotomy while 3 cases didn't need any additional maneuver. 
10 cases had pure anterior degenerative leaflet prolapse, 7 cases of them needed two artificial chordae attached to posteromedial and anterolateral papillary muscles, while 2 cases needed only one artificial chorda attached to posteromedial papillary muscle. Whereas triangular resection was done in only one case due to rupture group of secondary chorda attached anterior mitral leaflet and limited prolapsed area.

Shaving, thinning, decalcification and mobilization of the thickened, fibrotic and opaque anterior rheumatic leaflet was done in 6 cases, 3 cases of them needed concomitant mild shaving of the posterior leaflet and 2 cases needed a concomitant commissurotomy. 4 rheumatic cases needed artificial chordae due to anterior leaflet prolapse.

Bileaflet repair included 3 cases with degenerative valve pathology, 2 cases of them needed one artificial chorda attached from posteromedial papillary muscle to the anterior leaflet and rectangular resection was done to the posterior leaflet, while one case needed rectangular resection for the posterior leaflet and two artificial chordae attached to posteromedial and anterolateral papillary muscles.

Types of annuloplasty ring used in our repair were PHYSIO II RING (CARPENTIER-EDWARDS, CA, USA) in 57 cases and Medtronic Profile $3 D \AA$ in 43 cases. 11 rheumatic cases with predominant regurgitation and without commissural fusion or prolapse had just ring annuloplasty.

Minimal bilateral commissurotomy was done in 10 rheumatic cases, while chordal shortening was done for 3 rheumatic valve cases having anterior leaflet prolapse and anterolateral papillary muscle splitting was done in 4 rheumatic cases.

DEVAGA'S maneuver was done on beating heart for 20 cases with significant tricuspid regurgitation, 14 cases of them were rheumatic whereas 6 cases were degenerative (Table 3 ).

There was a significant difference between D and $\mathrm{R}$ groups as regards intraoperative MV area, MV mean diastolic gradient, AoX and CPB times, but there wasn't any significance difference as regards the degree of residual MR Fig. (4). The implanted ring size was significantly larger in D group than in the $\mathrm{R}$ group (mean ring size $32.0 \pm$ $1.8 \mathrm{~mm}$ versus $30.0 \pm 1.5 \mathrm{~mm}, p<0.0001$ ) (Table 3 ).

Predischarge inhospital echocardiographic examination revealed a significant difference between both groups as regards MPAP, MV area and MV gradient but there was no significance difference as regards degree of residual mitral regurgitation (Table 3).

\section{Follow-up:}

Clinical follow-up at 6 months showed a significance difference between both groups regarding NYHA class but the number of AF cases was the same with one patient in each group (Table 4).

Echocardiographic examination at 6 months revealed significant difference between both groups as regards MPAP, MV area, MV gradient and the degree of residual mitral regurgitation between both groups. Mean MV diastolic gradient in group "D" was $3.3 \pm 0.7 \mathrm{mmHg}$ while in group " $\mathrm{R}$ " it was $6.3 \pm 2.4 \mathrm{mmHg}$ and there was a high significance difference between both groups $(p<0.0001)$ (Table $5)$.

Five cases in group " $\mathrm{R}$ " had a mean diastolic mitral gradient more than $10 \mathrm{mmHg}$ and their values were $11,13,12,12$ and $13 \mathrm{mmHg}$, all needed mitral valve replacement. Three cases of them were post posterior leaflet shaving and decalcification and one patient was post anterior leaflet shaving and decalcification while one patient was post anterolateral papillary muscle splitting plus bilateral commissurotomy. These five cases underwent mitral valve replacement with a mechanical valve. St Jude Medical mechanical valve prosthesis (St. Jude Medical Inc, St. Paul, Minn) was used in 3 patient with sizes 29, 29 and 31, while CarboMedics (CM) bileaflet mechanical valve (Sorin Group, Milano, Italy) was used in 2 cases with sizes 27 and 31 .

Degree of residual mitral regurgitation in group "D" included $41(82 \%)$ cases with no regurgitation and trivial regurgitation while $9(18 \%)$ cases had mild mitral regurgitation, whereas in group " $R$ " $37(74 \%)$ cases had no regurgitation and trivial regurgitation, $9(18 \%)$ cases had mild mitral regurgitation, 2 (4\%) cases had mild to moderate one and $2(4 \%)$ cases had moderate mitral regurgitation that needed further follow-up with echocardiography every 6 months to evaluate the progress of regurgitation (Table 5).

\section{B- Comparison between resection versus respect techniques: \\ Operative results:}

The implanted ring size was significantly larger in respect group than in the resect group (mean ring size $32.8 \pm 1.3 \mathrm{~mm}$ versus $30.6 \pm 1.6 \mathrm{~mm}, p$ $<0.0001$ ) (Table 6). 
Aortic cross-clamping time in "Resect" group had mean of $71.8 \pm 8.0$ minutes while in "Respect" group" it had mean of $67.0 \pm 9.0$ minutes with a significance difference between both groups as resectional process was time consuming, wbut there was no significance difference as regards CPB time, it was related to increased number of tricuspid valve repair in "Respect" group" (Table $6)$.

\section{Follow-up:}

There was no significance difference between both groups as regards AF or NYHA class at six months of follow-up (Table 7).

As regards echocardiographic follow-up after 6 months there was significance difference between both groups for MVA, but no significance difference between both groups as regards degree of residual MV regurgitation or mean diastolic MV gradient (Table 8).

\section{Mortality:}

There was no mortality for any patient during study.

Table (1): Pre-operative echocardiographic parameters in cases with degenerative or rheumatic mitral valve disease.

\begin{tabular}{|c|c|c|c|c|c|c|c|}
\hline \multirow[t]{2}{*}{ Variable } & \multicolumn{2}{|c|}{$\begin{array}{l}\text { Degenerative } \\
\quad(\mathrm{n}=50)\end{array}$} & \multicolumn{2}{|c|}{$\begin{array}{l}\text { Rheumatic } \\
\quad(n=50)\end{array}$} & \multirow[t]{2}{*}{ Difference } & \multirow[t]{2}{*}{$95 \% \mathrm{CI}$} & \multirow{2}{*}{$\begin{array}{c}p \\
\text { value* }\end{array}$} \\
\hline & Mean & $\mathrm{SD}$ & Mean & SD & & & \\
\hline Pre-operative LA diameter $(\mathrm{cm})$ & 4.6 & 0.5 & 4.7 & 0.5 & 0.1 & -0.1 to 0.3 & 0.163 \\
\hline Pre-operative LVEDD $(\mathrm{cm})$ & 5.9 & 0.6 & 5.8 & 0.2 & -0.1 & -0.1 to 0.04 & 0.232 \\
\hline Pre-operative LVESD (cm) & 3.6 & 0.2 & 3.5 & 0.2 & -0.1 & -0.3 to -0.1 & 0.053 \\
\hline Pre-operative LV EF (\%) & 60.4 & 2.0 & 59.8 & 2.1 & -0.6 & -1.4 to 0.2 & 0.155 \\
\hline Pre-operative MPAP (mmHg) & 55.3 & 6.3 & 57.9 & 5.7 & 2.6 & 0.2 to 5.0 & 0.033 \\
\hline Pre-operative $\mathrm{MV}$ area $\left(\mathrm{cm}^{2}\right)$ & 3.4 & 0.4 & 2.6 & 0.3 & -2.2 & -2.4 to -2.1 & $<0.0001$ \\
\hline Pre-operative MV gradient ( $\mathrm{mmHg}$ ) & 2.4 & 0.8 & 10.4 & 1.8 & 8.0 & 7.4 to 8.6 & $<0.0001$ \\
\hline
\end{tabular}

Data are mean and standard deviation (SD).

$95 \% \mathrm{CI}=95 \%$ confidence interval. $*$ Unpaired $t$-test.

Table (2): Operative details in cases with degenerative or rheumatic mitral valve disease.

\begin{tabular}{|c|c|c|c|c|c|}
\hline Variable & Degenerative $(n=50)$ & Rheumatic $(n=50)$ & fference & $95 \% \mathrm{CI}$ & $p$-value* \\
\hline AoX time (min.) & $70.0 \pm 7.4$ & $52.9 \pm 7.9$ & -17.1 & -20.1 to -14.0 & $<0.0001$ \\
\hline CPB time (min.) & $105.3 \pm 11.1$ & $88.0 \pm 9.9$ & -17.3 & -21.5 to -13.1 & $<0.0001$ \\
\hline Intraoperative $\mathrm{MV}$ area $\left(\mathrm{cm}^{2}\right)$ & $2.7 \pm 0.3$ & $2.4 \pm 0.3$ & -0.3 & -0.4 to -0.2 & $<0.0001$ \\
\hline Intraoperative MV gradient ( $\mathrm{mmHg}$ ) & $3.2 \pm 0.7$ & $4.7 \pm 1.5$ & 1.5 & 1.19 to 2.0 & $<0.0001$ \\
\hline Mitral ring size & $32.0 \pm 1.8$ & $30.0 \pm 1.5$ & -2.0 & -2.7 to -1.3 & $<0.0001$ \\
\hline Variable & Degenerative $(n=50)$ & Rheumatic $(n=50)$ & $x^{2}$ & Df & $p$-value \\
\hline Tricuspid repair & $6(12.0 \%)$ & $14(28.0 \%)$ & 4.000 & 1 & $0.046 \#$ \\
\hline Intraoperative MR (trivial) & $7(14.0 \%)$ & $9 \quad(18.0 \%)$ & 0.295 & 1 & $0.587 \S$ \\
\hline
\end{tabular}

\section{Morbidity:}

There was no procedure-related post-operative morbidity such as thromboembolism, endocarditis, hemolysis or re-operation for valve dysfunction. Two cases were reopened for post-operative bleeding one was in degenerative group and the other was in the rheumatic one then they had a smooth post-operative course.

During the period of follow-up there wasn't any tricuspid regurgitation more than mild in the 20 cases underwent tricuspid repair.

No intra-operative or post-operative complications related to the use of the annuloplasty rings, valve repair techniques or artificial chordae (endocarditis, thromboembolism,...etc.) occurred. Four cases $(4.0 \%)$ had a persistence AF post-operatively needed to continue oral anticoagulant after 3 months of operation.

\section{Systolic anterior motion:}

No SAM was detected intraoperatively and no patient has required reoperation for SAM during our follow-up. 
Table (3): Post-operative (predischarge) echocardiographic variables in cases with degenerative or rheumatic mitral valve disease.

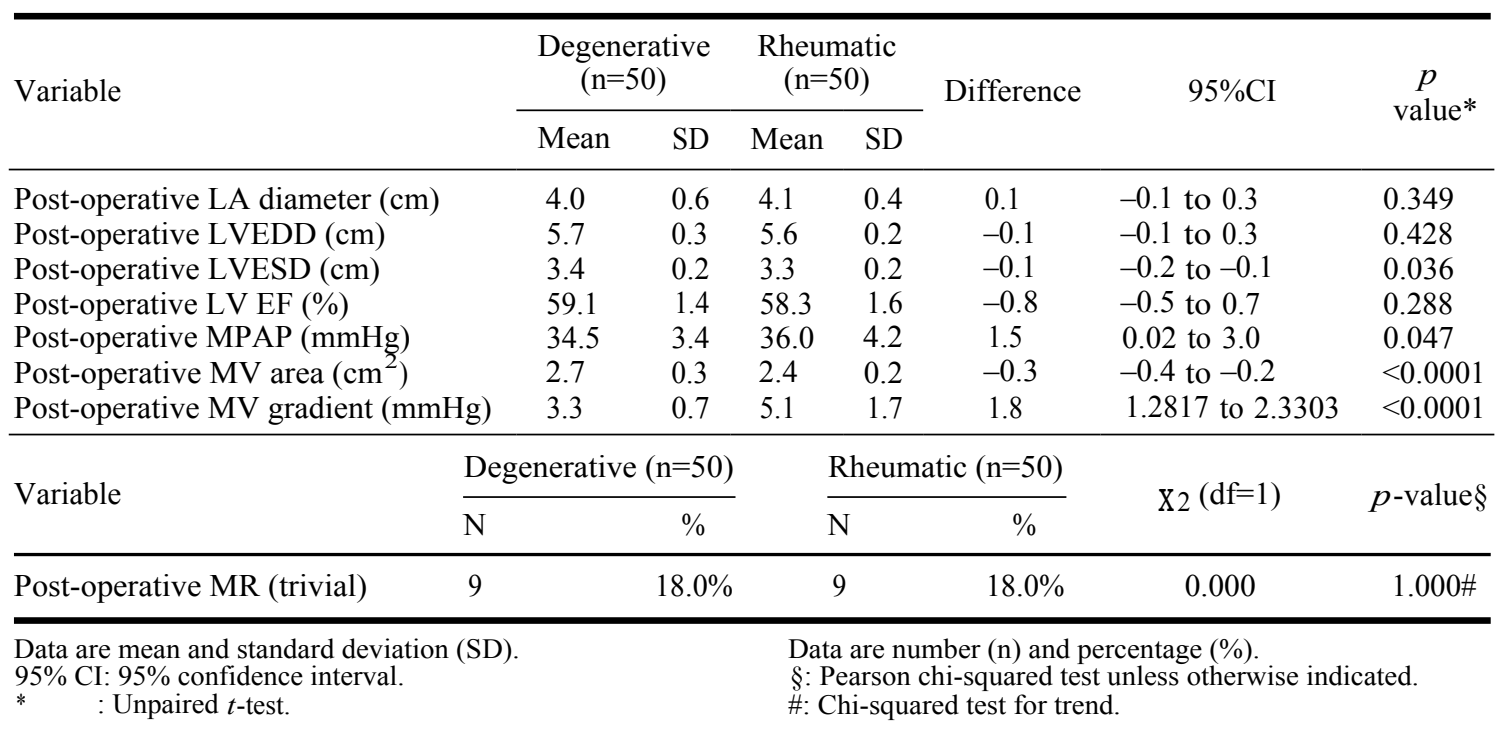

Table (4): NYHA class and incidence of AF at 6 months in cases with degenerative or rheumatic mitral valve disease.

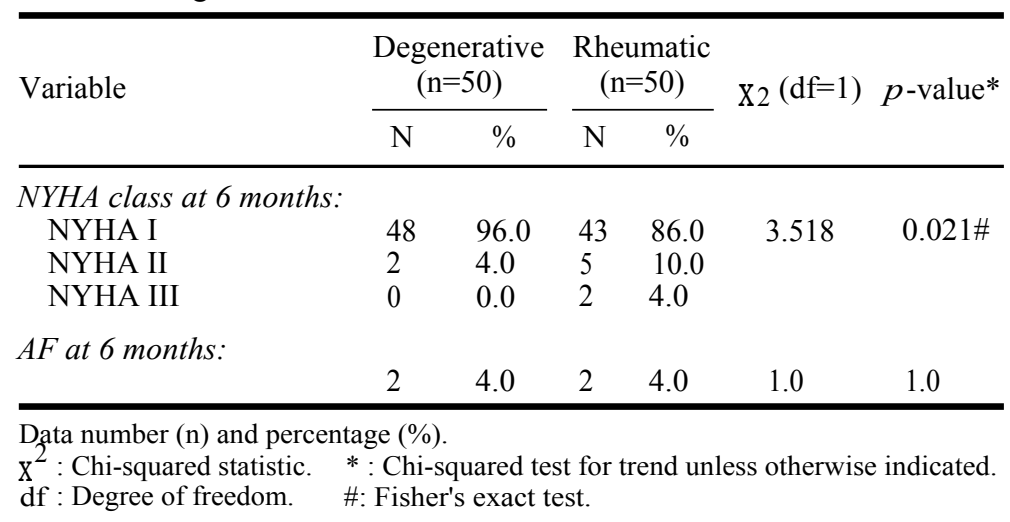

Table (5): Echocardiographic variables at 6 months in cases with degenerative or rheumatic mitral valve disease.

\begin{tabular}{|c|c|c|c|c|c|c|c|c|}
\hline \multirow{2}{*}{\multicolumn{2}{|c|}{ Variable }} & \multicolumn{2}{|c|}{$\begin{array}{l}\text { Degenerative } \\
\quad(\mathrm{n}=50)\end{array}$} & \multicolumn{2}{|c|}{$\begin{array}{c}\text { Rheumatic } \\
(\mathrm{n}=50)\end{array}$} & \multirow{2}{*}{ Difference } & \multirow{2}{*}{$95 \% \mathrm{CI}$} & \multirow{2}{*}{$\begin{array}{c}p \\
\text { value* }\end{array}$} \\
\hline & & Mean & $\mathrm{SD}$ & Mean & SD & & & \\
\hline \multicolumn{2}{|c|}{ LA diameter at 6 months $(\mathrm{cm})$} & 3.8 & 0.4 & 3.9 & 0.5 & 0.1 & -0.1 to 0.3 & 0.523 \\
\hline \multicolumn{2}{|c|}{ LVEDD at 6 months $(\mathrm{cm})$} & 5.3 & 0.5 & 5.2 & 0.2 & -0.1 & -0.2 to 0.1 & 0.136 \\
\hline \multicolumn{2}{|c|}{ LVESD at 6 months $(\mathrm{cm})$} & 3.1 & 0.3 & 3.0 & 0.2 & -0.1 & -0.2 to -0.1 & 0.041 \\
\hline \multicolumn{2}{|c|}{ LV EF at 6 months $(\%)$} & 60.5 & 1.7 & 59.9 & 1.9 & -0.6 & -2.3 to -0.9 & 0.285 \\
\hline \multicolumn{2}{|c|}{ MPAP at 6 months $(\mathrm{mmHg})$} & 32.3 & 3.4 & 35.0 & 8.0 & 2.7 & 0.3 to 5.2 & 0.029 \\
\hline \multicolumn{2}{|c|}{$\mathrm{MV}$ area at 6 months $\left(\mathrm{cm}^{2}\right)$} & 2.6 & 0.3 & 2.3 & 0.2 & -0.3 & -0.4 to -0.2 & $<0.0001$ \\
\hline \multicolumn{2}{|c|}{ MV gradient at 6 months ( $\mathrm{mmHg}$ ) } & 3.3 & 0.7 & 6.3 & 2.4 & 3.0 & 2.3 to 3.7 & $<0.0001$ \\
\hline \multirow{2}{*}{ Variable } & \multicolumn{3}{|c|}{ Degenerative $(n=50)$} & \multicolumn{3}{|c|}{ Rheumatic $(\mathrm{n}=50)$} & \multirow{2}{*}{$\mathrm{X}_{2}(\mathrm{df}=1)$} & \multirow{2}{*}{$p$-value $\S$} \\
\hline & $\mathrm{N}$ & & 0 & $\mathrm{~N}$ & & $\%$ & & \\
\hline \multicolumn{9}{|l|}{ MR at 6 months: } \\
\hline None & 25 & & .0 & 17 & & 34.0 & 4.517 & $0.034 \#$ \\
\hline Trivial & 16 & & 2.0 & 20 & & 40.0 & & \\
\hline Mild & 9 & & 8.0 & 9 & & 18.0 & & \\
\hline Mild to moderate & 0 & & 0 & 2 & & 4.0 & & \\
\hline Moderate & 0 & & & 2 & & 4.0 & & \\
\hline
\end{tabular}


Table (6): Operative details in cases undergoing resect or respect repair techniques.

\begin{tabular}{|c|c|c|c|c|c|}
\hline Variable & $\begin{array}{l}\text { Resect technique } \\
\qquad(\mathrm{n}=15)\end{array}$ & $\begin{array}{l}\text { Respect technique } \\
(\mathrm{n}=22)\end{array}$ & Difference & $95 \% \mathrm{CI}$ & $p$-value* \\
\hline AoX time (min) & $71.8 \pm 8.0$ & $67.0 \pm 9.0$ & 4.8 & 0.6 to 9.0 & 0.025 \\
\hline CPB time (min) & $107.0 \pm 13.5$ & $103.6 \pm 12.7$ & 4.5 & -2.0 to 10.9 & 0.171 \\
\hline Intraoperative $\mathrm{MV}$ area $\left(\mathrm{cm}^{2}\right)$ & $2.5 \pm 0.3$ & $2.8 \pm 0.2$ & 0.3 & 0.1 to 0.4 & 0.003 \\
\hline Intraoperative MV gradient $(\mathrm{mmHg})$ & $3.3 \pm 0.5$ & $3.1 \pm 0.8$ & -2.0 & -0.6 to 0.2 & $\begin{array}{c}0.023 \\
<00001\end{array}$ \\
\hline Mitral ring size $(\mathrm{mm})$ & $30.6 \pm 1.6$ & $32.8 \pm 1.3$ & 2.1 & 1. 3 to 3.0 & \\
\hline Variable & $\begin{array}{l}\text { Resect technique } \\
\qquad(\mathrm{n}=15)\end{array}$ & $\begin{array}{l}\text { Respect technique } \\
\quad(\mathrm{n}=22)\end{array}$ & $x^{2}$ & Df & $p$-value \\
\hline Tricuspid repair & $1(6.7 \%)$ & $5(22.7 \%)$ & & & $0.387 \#$ \\
\hline Intraoperative MR (trivial) & $2(13.3 \%)$ & $5(22.7 \%)$ & 0.301 & 1 & $0.463 \S$ \\
\hline $\begin{array}{l}\text { Data are mean } \pm \text { SD or number }(\%) \text {. } \\
95 \% \text { CI: } 95 \% \text { confidence interval. } \\
\chi^{2} \quad \text { : Chi-squared statistic. }\end{array}$ & $\begin{array}{l}\text { Df: Degree of } \\
*: \text { Unpaired }\end{array}$ & otherwise indicated. & & $\begin{array}{l}\text { Fisher's exact } \\
\text { Chi-squared te }\end{array}$ & est. \\
\hline
\end{tabular}

Table (7): Incidence of AF and NYHA class at 6 months in cases undergoing resect or respect technique.

\begin{tabular}{|c|c|c|c|c|c|c|}
\hline \multirow{2}{*}{ Variable } & \multicolumn{2}{|c|}{$\begin{array}{l}\text { Resect technique } \\
\qquad(\mathrm{n}=15)\end{array}$} & \multicolumn{2}{|c|}{$\begin{array}{l}\text { Respect technique } \\
\qquad(\mathrm{n}=22)\end{array}$} & \multirow{2}{*}{$\begin{array}{c}x^{2} \\
(\mathrm{df}=1)\end{array}$} & \multirow{2}{*}{$\begin{array}{c}p- \\
\text { value* }\end{array}$} \\
\hline & $\mathrm{N}$ & $\%$ & $\mathrm{~N}$ & $\%$ & & \\
\hline \multicolumn{7}{|c|}{ NYHA class at 6 months: } \\
\hline NYHA I & 14 & 93.3 & 21 & 95.5 & 1.215 & 0.613 \\
\hline NYHA II & 1 & 6.7 & 1 & 4.5 & & \\
\hline \multicolumn{7}{|c|}{ AF at 6 months: } \\
\hline- & 14 & 93.3 & 21 & 95.5 & - & $0.761 \#$ \\
\hline+ & 1 & 6.7 & 1 & 4.5 & & \\
\hline
\end{tabular}

Table (8): Echocardiographic variables at 6 months in cases undergoing resect or respect technique.

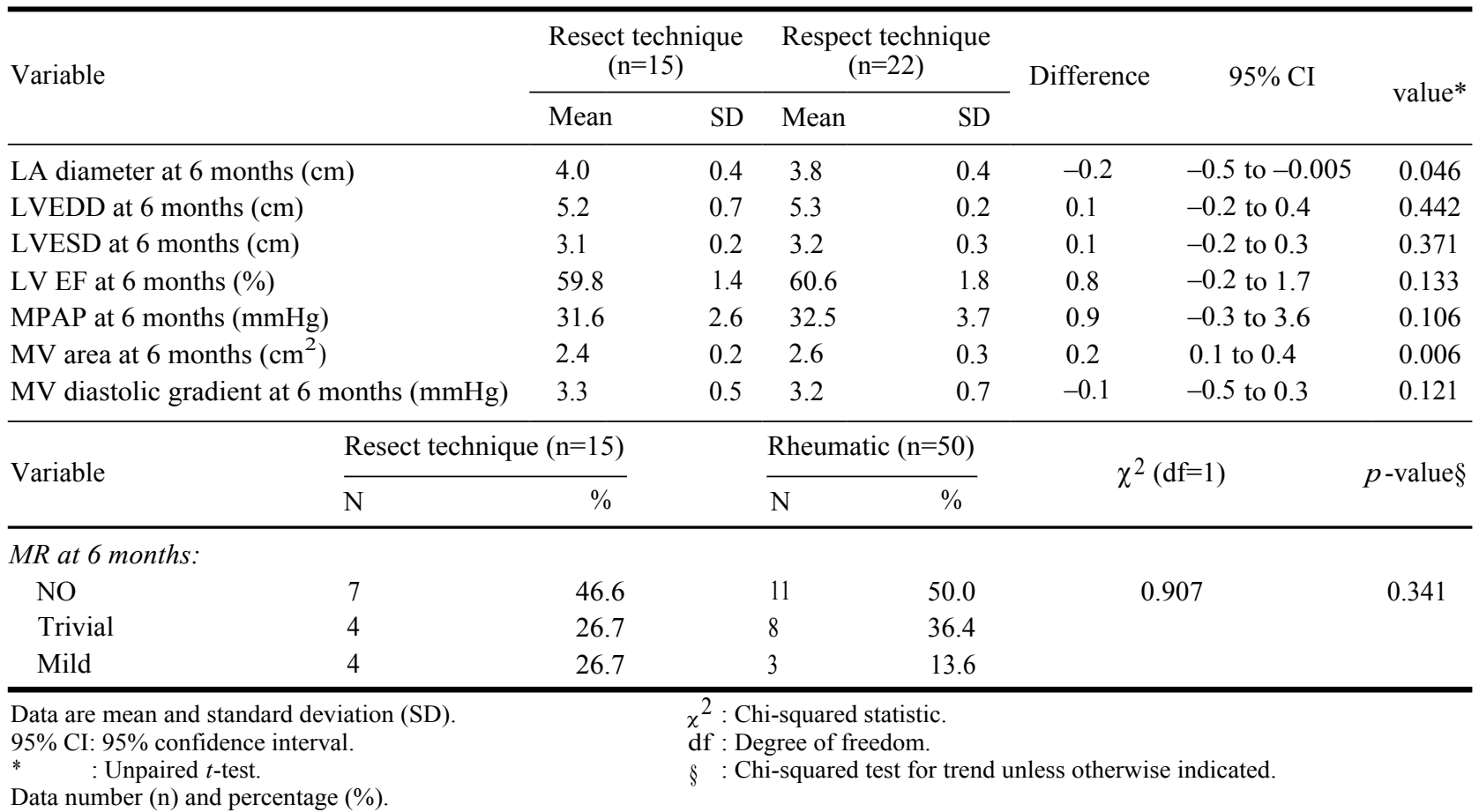




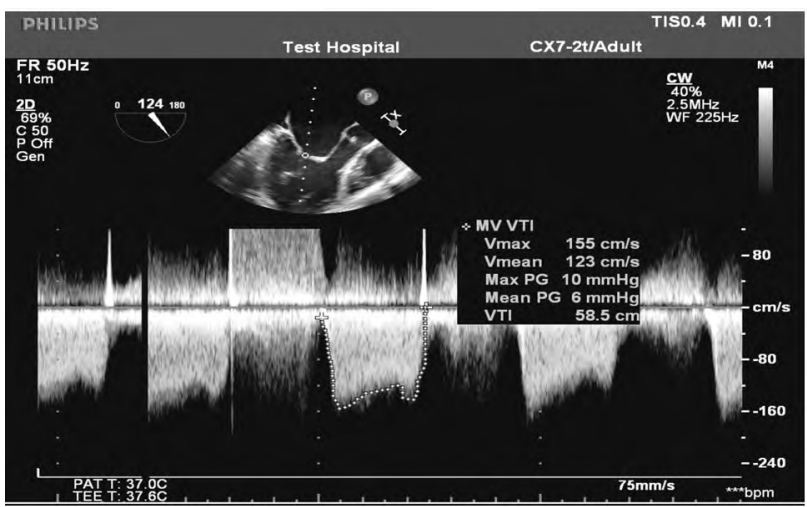

Fig. (1): Intraoperative TEE before mitral valve repair with severe mitral regurgitation.

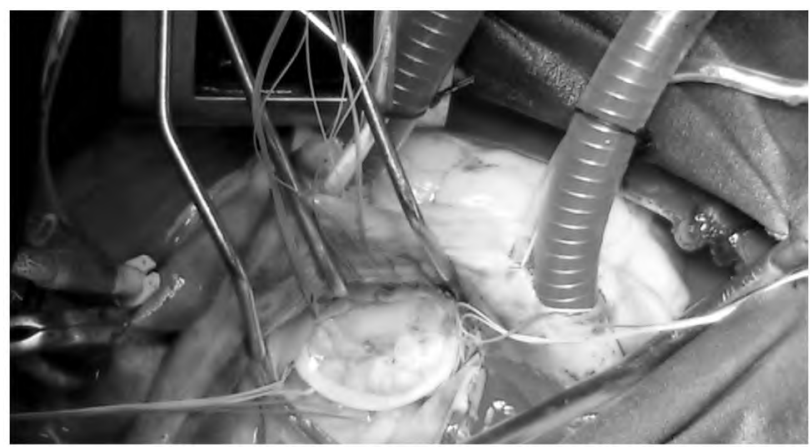

Fig. (3): Mitral valve with well coapted leaflets after respect technique repair and ring annuloplasty insertion.

\section{Discussion}

Greater understanding of the structure, function and pathology of the MV in recent decades improved the surgical results of MV repair, leading to excellent long-term survival [11].

McNeely and Vassileva [1] documented the short-term advantage of mitral valve repair versus other surgical options including replacement. They included lower operative mortality, improved survival, better preservation of left-ventricular function, shorter post-operative hospital stay, lower total costs, and fewer valve-related complications, including thromboembolism, anticoagulationrelated bleeding events and late prosthetic dysfunction.

We had no mortality or valve related morbidity in our study during our short time follow-up. If proper technique has been in degenerative group and proper selection of rheumatic cases were done there would be no significance difference, however when we applied shaving and decalcification in an effort to increase the mobility and pliability of thickened and heavily fibrotic leaflet or leaflets the results weren't be encouraging.

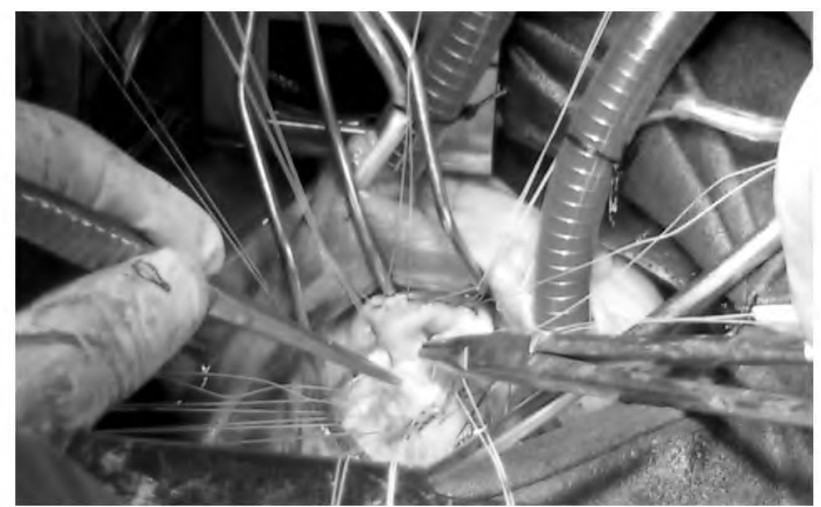

Fig. (2): Respect technique using uniscalloping maneuvar and suturing the adjacent portion of the posterior leaflet.

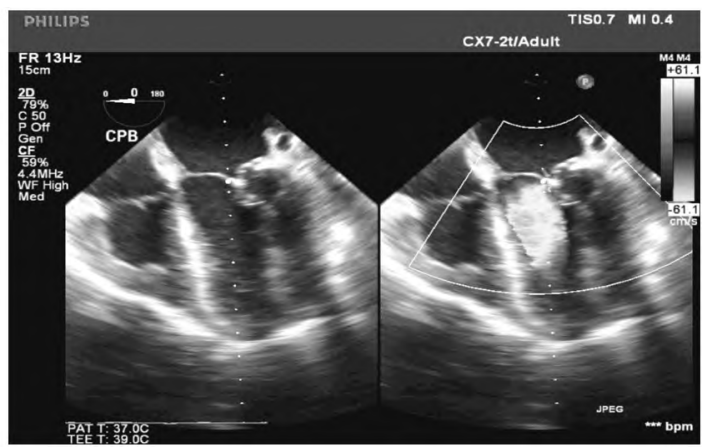

Fig. (4): Intraoperative TEE post degenerative posterior mitral valve repair with no mitral regurgitation.

Feasibility of mitral valve repair in rheumatic pathology depended on presence of predominant mitral valve regurgitation, mean diastolic gradient, mobility and pliability, and Height of AML $>2.4 \mathrm{~cm}$. We used mean diastolic mitral valve gradient as an important and sole parameter for mitral stenosis diagnosis either pre-operatively or post-operatively.

Jebara et al., [14] mentioned that diagnosis of post mitral repair stenosis depends on high transvalvular gradients greater than or equal to 8 to 10 $\mathrm{mmHg}$ by Doppler.

Only five cases (5\%) of the whole study-needed reoperation during our follow-up due to high diastolic gradient across the mitral valve, all were post rheumatic valve repair, with no cases needed reoperation post degenerative valve repair and two cases with moderate mitral valve regurgitation needed echocardiography follow-up every 6 months.

Geldenhuys and colleagues [15] mentioned that leaflet procedures may be associated with reduced durability of rheumatic MV repair.

Another opinion explaining the poor outcome of rheumatic leaflet repair was taken by Dillon et 
al., [16] stating that the leaflet procedures may not be the direct cause of the reduced durability of valve repair, but rather a surrogate marker for advanced mixed mitral disease explaining the poorer durability associated with these procedures.

We faced difficulties in repairing calcified and restricted anterior or posterior leaflets during shaving and decalcification process. During our six months follow-up, mean diastolic MV gradient had a significant difference between both rheumatic and degenerative groups. Five cases had a mean diastolic MV gradient more than $10 \mathrm{mmHg}$ all were in the rheumatic groups. Four cases of them were post leaflets shaving and decalcification divided as three cases were post posterior leaflet shaving and decalcification and one patient was post anterior leaflet shaving and decalcification, while one patient was post anterolateral papillary muscle splitting plus bilateral commissurotomy. These five cases underwent mitral valve replacement with mechanical valves.

Madesis et al., [17] explained the poor outcome of shaving and decalcification of the mitral leaflets stating that mixed lesion (MR + MS) with a rigid and retracted small posterior or anterior leaflet often present unfavorable findings for adequate repair and subsequently fail.

Yakub et al., [10] mentioned in his study that repairing of mixed lesions is technically more challenging than managing of pure MR lesions. Durability of pure MR repair is much higher than that of mixed lesion repair.

Mitral valve repair techniques popularized in the last decade include the use of artificial chordae with extended PolyTetraFluoroEthylene (ePTFE) sutures for anterior and posterior mitral leaflet pathology. These technical improvements have enabled the successful repair of more complex MV disease [12].

In our study we used artificial chordae tendineae as a standard to anterior mitral leaflet prolapse mainly, however it might be used in concomitant with uniscalloping of posterior leaflet in respect technique for posterior mitral leaflet prolapse. In general we did our best not to resect any of AML except in one case when AML was voluminous and the prolapsed portion was very limited.

Very limited prolapse of the anterior leaflet can be treated by a small triangular resection of the prolapsed area followed by direct closure with interrupted sutures. The triangular resection should be limited to the rough zone for not compromising the body of the leaflet [13].

Perier et al., [7] considered the respect approach as the technique of choice when quality and quantity of posterior degenerative leaflet tissue is adequate to achieve a smooth and regular surface. However, there are some limitations to this technique. Excessive and exuberant myxomatous degeneration can render the posterior leaflet irregular with bulging deformations that need to be resected to obtain a regular surface of coaptation so they consized the use of the respect approach if there was a limited prolapsed portion of the posterior leaflet.

This concept coincides with us in our strategy in repairing of PPL in the degenerative mitral valve as we used respect approach if there was a limited prolapse of posterior leaflet.

When we compared between respect and resection group as techniques used for repair of PLP in the degenerative valve, we identified the prolapsed portion which was usually due to elongated chordae tendineae or rupture chordae supporting this portion as: If the prolapsed portion was small (involving part of middle scallop) we used the respect technique and if the prolapsed portion was extensive (including all the middle scallop), we used the rectangular resection valve repair.

Seeburger et al., [18] also compared the results of respect technique versus resection one for repair of isolated posterior mitral leaflet prolapse but with slight increase of numbers of reoperations and mortality in the resectional group more than the respect one. They issued this for longer line of coaptation occurred in the respect group that has been shown to be associated with better long-term durability of respect group after MV repair for mitral regurgitation.

There was no difference between both groups as regards morbidity or mortality. No cases needed reoperation due to high mitral valve diastolic gradient or increased the degree of residual MR. Also no cases complicated with SAM in any group. We used leaflet plication during our repair when needed.

The differences between both groups postoperatively were bigger MVA, less mean diastolic mitral gradient and larger ring annuloplasty size in the respect group than the resect one, while after 6 months there was a still significance difference as regards MVA but no difference for mean diastolic mitral gradient. 
Chan and colleagues [19] found that cases with mean intraoperative mitral transvalvular gradients greater than $3 \mathrm{mmHg}$ were predominantly treated with a resection strategy, whereas cases with mean gradients of $3 \mathrm{mmHg}$ or less were predominantly treated with a leaflet preservation strategy.

The special configuration of the middle scallop evokes a spinnaker with a large bulging surface area submitted to full systolic stress explaining the higher frequency of $\mathrm{P} 2$ prolapse in comparison to P1 and P3 which have smaller surface area [20].

During PL repair we depended mainly on the role of which part PL was prolapsed If the prolapsed portion was small-part of $\mathrm{P} 2$ scallop-we used the respect technique and if the prolapsed portion was extensive we used the resectional one, but mean diastolic mitral gradient was considered as an important parameter in mitral valve prognosis.

Milaljevic et al., [21] used resectional technique and respect one with artificial neochordae for mitral valve repair. No mortality or morbidity was detected in any group, also no SAM was complicated during short term follow-up. The only difference between both groups was shorter operation time in respect group than the resectional one. They considered respect technique as a good choice for cases with limited posterior leaflet prolapsed. To avoid SAM, the degree of correction of the PPL must be operated to make the coaptation surface remains vertical, posterior, and parallel to the posterior wall of the left ventricle in its inflow region. Leaflet plication may be used when needed to avoid SAM during posterior leaflet repair with a high successful rate.

Takai et al., [22] compared the midterm outcome of mitral valve repair with respect technique with using artificial chordae versus the resectional one for only posterior leaflet disease. There wasn't any valve related complications in any group or mortality. The only differences between both groups post-operatively were bigger MVA, less mean diastolic gradient and larger ring annuloplasty size in the respect group than the resect one. They appreciated using of larger size of ring annuloplasty in prevention of SAM for the respect group.

This matched with our results in the presence of bigger MVA, larger ring annuloplasty size in the respect group and greater post-operative mean diastolic gradient in the resect group, with no mortality or valve related morbidity in short term follow-up. We also consider the use of ring annuloplasty as a must during mitral repair. We also considered the use of a larger size of ring annulo- plasty in respect group as a benefit for SAM prevention.

Tomasic et al., [23] stated that the cause of elevated post-operative mean diastolic gradients in the resectional group could be a result from excessive leaflet resection and thus possibly related to the technical execution of the resect technique rather than the technique itself. Furthermore, because ring sizing is based on the surface area of the anterior leaflet, the larger annuloplasty ring sizes found in the respect group indicate larger mitral valve orifice areas.

Finally we found that MV repair in the degenerative cases and selected rheumatic ones gives good results with low intraoperative mortality and low late valve related morbidity. It is worse to mention that shaving and decalcification of the rheumatic valve repair didn't give us a promising results, where four cases of total eighteen cases needed reoperation as a result of thickened, heavily fibrotic and calcified rheumatic leaflets. Otherwise our results of other pathologies repairs were good and encouraging.

\section{Conclusion:}

Rheumatic valve repair appears to be possible in selected cases and repairing of mixed rheumatic lesions is technically more challenging than managing of predominant MR lesions. Leaflet procedures in rheumatic valve repair may be associated with reduced durability of rheumatic MV repair. Increasing the degree of calcification either in the subvalvular apparatus or in the commissures, thickening of the leaflets and calcification of any valvular component decreases the success of the rheumatic repair.

The early post-operative results for posterior mitral leaflet repair with respect technique using uniscalloping of posterior leaflet or artificial chordae-ePTFE-is very acceptable and recommended.

Correction of the prolapse of anterior mitral leaflet remains a challenging procedure as plication or resection of the anterior leaflet was reported to be unfavorable and not applicable to a large area of prolapse and using artificial chordae may be a good option for cases with a large prolapsed area. Triangular resection for AML had a very limited use just if AML was voluminous and the prolapsed portion was very limited.

Mitral annuloplasty is a must for a durable mitral valve repair, as it provides an efficient annular remodeling and reduces the annular dimension leading to increase coaptation length. This, 
in turn, reduces leaflet stress and provides the basis for a durable repair.

\section{References}

1- McNEELY C.A. and VASSILEVA C.M.: Long-term outcomes of mitral valve repair versus replacement for degenerative disease: A systematic review. Curr. Cardiol. Rev., 11 (2): 157-62, 2015.

2- MORIMOTO Y. and SUGIMOTO T.: Alfieri stitch for temporary severe functional mitral regurgitation after aortic valve replacement. Morimoto and Sugimoto. Surgical Case Reports, 4: 4, 2018.

3- KOPRIVANAC M., MARTA K., SHEHAB A., et al.: Degenerative mitral valve disease-contemporary surgical approaches and repair techniques Ann. Cardiothorac. Surg., 6 (1): 38-46, 2017.

4- TORII S., ROMERO E.M., MORI H., et al.: The spectrum of mitral valve pathologies: Relevance for surgical and structural interventions Expert Review of Cardiovascular Therapy, 15 (7): Pages 525-35, 2017.

5- TSUKUI H., NOBUHIRO U., HIROYUKI S., et al.: Early outcome of folding mitral valve repair technique withou resection for mitral valve prolapse in 60 patient the Journal of Thoracic and Cardiovascular Surgery January, 145 (1): Pages 1686-7, 2013

6- RIM Y., LAING T.S., DAVID D.H. and KIMY H.: Mitral Valve Repair Using ePTFE Sutures for Ruptured Mitral Chordae Tendineae: A Computational Simulation Study Annals of Biomedical Engineering, January, 42 (1): 13948, 2014.

7- PERIER P., HOHENBERGER W., LAKEW F. and DIEGELE A.: Prolapse of the posterior leaflet: Resect or respect Ann. Cardiothorac. Surg., 4 (3): 273-7, 2015.

8- ZANOBINI M., RICCIARDI G. and MAMMANA L.F.: The 'respect rather than resect' principle in mitral valve repair: The lateral dislocation of the P2 technique. Journal of Cardiovascular Medicine Sep., 18 (9): 687-90, 2017.

9- De OLIVEIRA J.F. and ANTUNES J.M.: Mitral Valve Repair: Better Than Replacement. Heart, 92: 275-81, 2006.

10- YAKUB M.A., DILLON J., MOORTHY P.S., et al.: Is rheumatic aetiology a predictor of poor outcome in the current era of mitral valve repair? Contemporary longterm results of mitral valve repair in rheumatic heart disease. Eur. J. Cardiothorac. Surg., 44: 673-81, 2013.

11-LAZAM S., VANOVERSCHELDE J.L., TRIBOUILLOY C., et al.: MIDA (Mitral Regurgitation International Database) Investigators: Twenty-Year Outcome After Mitral Repair Versus Replacement for Severe Degenerative Mitral Regurgitation: Analysis of a Large, Prospective,
Multicenter, International Registry. Circulation. Jan., 31, 135 (5): 410-22, 2017.

12- RIM Y., LAING T.S., DAVID D.H. and KIMY H.: Mitral Valve Repair Using ePTFE Sutures for Ruptured Mitral Chordae Tendineae: A Computational Simulation Study Annals of Biomedical Engineering, January, 42 (1): 13948, 2014.

13- ADAMS D.H., ANYANWU A.C., RAHMANIAN P.B. et al.: Large Annuloplasty Rings Mitral Valve. Ann. Thoracic. Surg., 82 (6): 2096-101, 2006.

14- JEBARA V.A., MIHAILEANU S., ACAR C., et al.: Left ventricular outflow tract obstruction after mitral valve repair. Results of the sliding leaflet technique. Circulation, 88: 30-4, 1993.

15- GELDENHUYS A., KOSHY J.J., HUMAN P.A., et al.: Rheumatic mitral repair versus replacement in a threshold country: The impact of commissural fusion. J. Heart Valve Dis., 21: 424-32, 2012

16- DILLON J., YAKUB M.A., PAU K.K. and TAIB M.E. Leaflet extension for repairing rheumatic mitral valve regurgitation Ann. Cardiothorac. Surg., May, 4 (3): 3013, 2015 .

17- MADESIS A., TSAKIRIDIS K., ZAROGOULIDIS P., et al.: Review of mitral valve insufficiency: Repair or replacement. Journal of Thoracic Disease, Mar., 6 (Suppl 1): S39-S51, 2014.

18- SEEBURGER J., FALK V., BORGER M.A., et al.: Chordae Replacement Versus Resection for Repair of Isolated Posterior Mitral Leaflet Prolapse: À Ègalité. Ann. Thorac. Surg., 87: 1715-20, 2009.

19- CHAN V., CHU M.W.A., LEONG-POI H., et al.: Randomised trial of mitral valve repair with leaflet resection versus leaflet preservation on functional mitral stenosis. B.M.J. Open, 7: e 015032, 2017.

20- FAN J., TIMBROOK A., SAID S., et al.: Myxomatous Mitral Valve with Prolapse and Flail Scallop. Pol. J. Radiol., 81: 233-5, 2016.

21- MIHALJEVIC A., GREGORY P., GILLINOV A.M., et al.: Robotic Posterior Mitral Leaflet Repair: Neochordal Versus Resectional Techniques Ann. Thorac. Surg., 95: 787-94, 2013.

22- TAKAI H., TANABE H., YAMABE T., et al.: Midterm Outcome of Mitral Valve Repair with Artificial Chordae for Only Posterior Leaflet Disease-Comparison with the Resectional Technique in a Single Institute. Ann. Thorac. Cardiovasc. Surg., 22: 32-7, 2016.

23- TOMSIC A.L., HIEMSTRAB Y., STEPHANIE L., et al. Early and long-term outcomes of mitral valve repair for Barlow's disease: A single-centre 16-year experience. Interactive CardioVascular and Thoracic Surgery, 26 783-9, 2018. 


\section{الطرق الحديثة فى إصلاح الصمام الميترالى}

تعتبر عملية إصلاح الصمام الميترالى من الآفضلية ما تفوق عملية الإستبدال. حيث يؤدى الإصلاح إلى تحسن نسبة البقاء على قيد الحياة

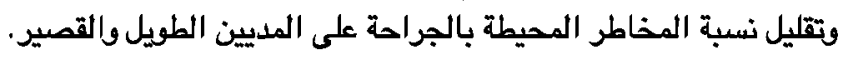

آجريت هذه الدراسة على مئة مريض مصاب بإرتجاج شديد فى الصمام الميترالى إما نتيجة لتنكس آو روماتيزم. وقد تم تقسيم المرضى المي

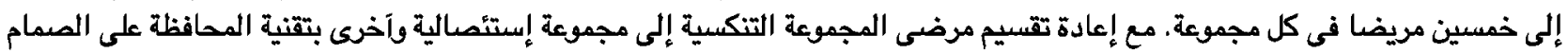
الميترالى.

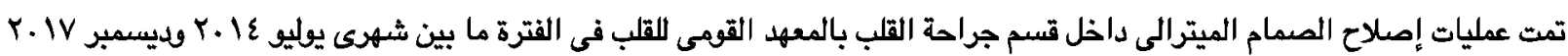
مع فترة متابعة اللنتائج تمتد إلى ستة آثشهر .

وقد تم إعتماد الموجات فوق الصوتية لعضلة القلب كطريقة موثقة للتقييم فى المرضى لما قبل العملية مع الإعتماد على الحالة الإكلينيكية كطريقة آخرى فى التقييم.

وقد خلصت التتائج إلى آفضلية إصلاح الصمام الميترالى فى الحالات التنكسية عن نظيراتها الروماتيزمية مع وجود إمكانية لإصلاح الصمام

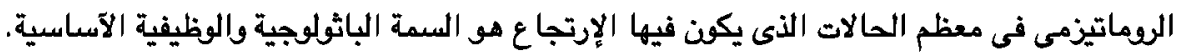
كما آبرزت النتائج دور الحلقات الطوقية فى إصلاح الصمام الميترالى آيا كان نوع العيب.

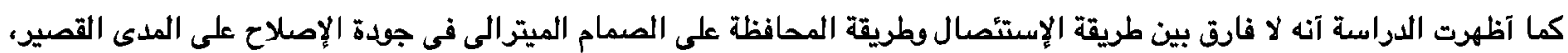

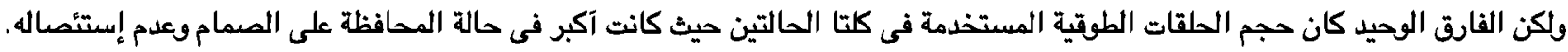

